\title{
Cuerpos en el espejo de la política feminista
}

\author{
Bodies in the mirror of political feminism
}

GEMMA DEL OLMO CAMPILLO*

\begin{abstract}
Resumen: Para Carla Lonzi, la cultura se sostiene sobre el desprecio de lo femenino, por lo que es indispensable y urgente un cambio radical. Solo a través del reconocimiento de la valía de las mujeres es posible salir de la situación de menosprecio, y esto solo se consigue mediante la elaboración de una nueva cultura que no instrumentalice a las personas y sea más respetuosa con las diferencias. Un espacio en el que puede iniciarse esta transformación, en opinión de Lonzi, es en los grupos de autoconciencia, porque es donde se vuelven visibles estas arbitrariedades que hacen invivible la vida de las mujeres y donde se piensa la manera de hacer modificaciones reales. Una de las características principales de estos grupos de autoconciencia es la búsqueda de la propia libertad con ayuda de las otras, para evitar así autoengaños. La política que llevan a cabo pretende re-construir por completo la sociedad a partir de la reconstrucción de sí, con el fin de conseguir una sociedad en la que no se menosprecie a nadie.

Palabras clave: Grupos de autoconciencia, política de mujeres, cultura, autenticidad, reconocimiento.
\end{abstract}

\begin{abstract}
For Carla Lonzi culture is sustained on the contempt of the feminine, which makes radical change urgent and indispensable. Only through the recognition of the value of women is it possible to end the situation of their depreciation, and this can only be realized through the development of a new culture; one which does not instrumentalize people and gives more respect to difference. One space in which this transformation can be initiated, in Lonzi's opinion, is in consciousness raising groups. In these groups the arbitrary circumstances which make women's lives unlivable can be exposed and ways can be considered to carry out true change. One of the principal characteristics of consciousness raising groups is the search for self-liberation, with the help of other participants to avoid self-deception. The aim is to thoroughly reconstruct society with the goal of achieving a society in which nobody is depreciated.
\end{abstract}

Keywords: consciousness raising groups, women's politics, culture, authenticity, recognition.

Carla Lonzi es conocida sobre todo por su obra Escupamos sobre Hegel, en la que, entre otras cosas, hace una dura crítica a la cultura. En su opinión, la cultura es una elaboración masculina nefasta para las mujeres porque afirma y promueve la inferioridad de la mujer ${ }^{1}$. Considera que no hay ningún aspecto de esta que no implique el menosprecio hacia las

Fecha de recepción: 13/05/2016. Fecha de aceptación: 17/07/2016.

* Docente de la Universidad de Zaragoza. Líneas principales de investigación: Pensamiento feminista y Filosofía española. Ha publicado, entre otros artículos: «La voz de Antígona: Entre la vida y la muerte», Thémata. Revista de Filosofia, n. 46, 2012, pp. 421-426; y «Diferencias al límite de la ruptura», Revista Eikasia, n. 70, 2016, pp. 57-76. Contacto: gdelolmo@unizar.es

1 Lonzi, C., Escupamos sobre Hegel. Y otros escritos de Liberación femenina, Buenos Aires, La Pleyade, 1975 , p. 9 . 
mujeres: toda elaboración cultural lleva ya implícita la jerarquía de los sexos² ${ }^{2}$ Ni el arte, ni la religión, ni las propuestas políticas de cambio social como el marxismo, no hay nada a salvo de la arbitrariedad de beneficiar lo masculino en detrimento de lo femenino.

Si esto es así, si la cultura es un espacio imposible para que las mujeres tengan alguna posibilidad de escapar de una vida que es invivible ${ }^{3}$, si es la causa principal de su conformación como seres subordinados, entonces la manera de tener alguna perspectiva de ser libres será saliendo de esa cultura que margina. Pero ¿cómo hacerlo? No es sencillo, evidentemente, pero para Lonzi no hay otra alternativa: resulta imposible la libertad de las mujeres dentro de una cultura masculina.

Esta idea, en la actualidad, es probable que resulte sorprendente. La propuesta de salir de la cultura parece que nos lleva a situarnos en una especie de estado de naturaleza, pero esto está muy lejos del planteamiento de Lonzi. No se trata de vivir en nada parecido a una situación natural anterior a la cultura, algo por otra parte inviable, sino que, en mi opinión, la clave está en hacer una interpretación teniendo en cuenta la influencia de las teorías marxistas en la Italia de los años 70. La propuesta de Lonzi, a mi juicio, está en la línea de afirmar que los cambios necesarios para la libertad solo serán verdaderos cambios, esto es, realmente posibilitarán la libertad de hombres y mujeres, si se trata de transformaciones que van a la raíz del problema y están impulsados desde la vida y necesidades de las personas que quieren esas modificaciones. La renovación no puede ser promovida por quienes tienen el poder y detentan lugares de privilegio, sino que debe ser conducida por quienes quieren y precisan el cambio, por las personas que tienen deseos y necesidades reales de transformar la situación.

Así, lo que propone Lonzi son modificaciones estructurales en las formas de vida y de relación de hombres y mujeres para generar una nueva cultura más libre, ajena a los distintos modelos de dominación y sometimiento. Esa es su propuesta de «desculturación» ${ }^{4}$, ir a la raíz del problema, que no es otro que la actual configuración de una cultura basada en el menosprecio de lo femenino, y hacer las transformaciones necesarias para posibilitar otra nueva cultura.

De manera que la única forma de que haya alguna posibilidad de que las mujeres sean valoradas y, por tanto, no sean sujetos marginados por la sociedad ${ }^{5}$, es un cambio radical que dará origen a una nueva forma de convivencia en la que no haya desprecios ni sometimientos ni falsedades. Lonzi es muy crítica con las producciones culturales que han legitimado las situaciones de desigualdad, considera que son ideología y que tienen el objetivo claro de convertir en razonables comportamientos y valoraciones que no lo son.

2 Rivolta Femminile, «Manifesto de Rivolta», en: Lonzi, C., Escupamos sobre Hegel, p. 17.

3 Lonzi, C., Vai pure. Dialogo con Pietro Consagra, Milán, Et al Edizioni, 2011, p. 30.

4 Lonzi, C., Escupamos sobre Hegel, p. 45.

5 La relación entre el desprecio social y una existencia difícil la articula de forma muy clara Kate Millett en su obra Política sexual: «Cuando la personalidad tropieza con imágenes tan denigrantes de sí misma en la ideología, la tradición y las creencias sociales, resulta inevitable que sufra un grave deterioro. Teniendo en cuenta, además, el descrédito sutil pero constante que suponen cotidianamente para la mujer sus relaciones personales, las impresiones que recoge de los medios de información y la discriminación que padece en lo tocante a la conducta, al trabajo y la educación, no cabe extrañarse de que desarrolle ciertos rasgos de grupo característicos de los individuos que, en virtud de su posición minoritaria, llevan una vida marginada en la sociedad». Millett, K., Política sexual, Madrid, Cátedra, 2010, p. 119. 
Para evitar que cualquier ideología consiga convencer o manipular a la gente, el planteamiento de Lonzi es que las modificaciones estructurales y, por tanto, la construcción de una nueva cultura, tendrá que nacer de necesidades reales, es decir, de los deseos concretos y particulares de libertad originados en las exigencias reales surgidas de la vida cotidiana. Solo así será posible que la nueva cultura refleje un deseo de libertad auténtico, generado a partir de necesidades vitales y no de teorías políticas o filosóficas. Una vez desvelada la labor de la cultura, no se puede seguir confiando en sus posibilidades de mejora ni tampoco mantener la misma situación por más tiempo. No se pueden depositar las esperanzas en ninguna ideología ni tampoco esperar a que la sociedad vaya a hacer algo a favor de las mujeres, porque los hombres beneficiados por el poder, en su mayoría, no están interesados en cambiar las cosas y las mujeres no pueden hacerlo porque no ocupan lugares de poder.

Pero en su mano sí está iniciar modificaciones en su propia vida. La idea es que cada cual, en su proceder cotidiano, voluntariamente, porque ha tomado conciencia de la situación injusta en la que viven las mujeres, modifique su manera de actuar y de relacionarse. Esos cambios terminarán generando una nueva cultura, esta vez más libre y auténtica, debido a que su origen está en la conciencia crítica hacia las desigualdades e injusticias y, además, respondería a deseos y necesidades reales.

Una nueva estructura dará lugar a una nueva cultura, esta vez elaborada desde la libertad y la autenticidad. Esto, claro está, no es nada fácil. Ella es consciente de que supone un enorme ejercicio de crítica y autocrítica, dado que gran parte de los aspectos que hemos hecho propios, y así los consideramos, están aprendidos dentro una cultura, forman parte de ella. En otras palabras, nos desarrollamos, actuamos, entendemos y pensamos dentro de los códigos de una cultura, ponerlos en cuestión supone, en gran medida, ponernos en cuestión y poner en cuestión la propia vida, así como la de las personas que tenemos a nuestro alrededor.

Pero esta es, precisamente, su propuesta: ponerse en cuestión, y hacerlo de forma radical, en todos los aspectos de la existencia. Tanto en lo más obvio como son las relaciones en el ámbito familiar, por ejemplo, hasta en lugares menos evidentes y más turbadores, como pueden ser las propias prácticas sexuales. Si queremos una cultura libre que impregne toda la sociedad, tendrá que nacer de las verdaderas necesidades de libertad de la gente, y de la justicia que requieran.

«El sujeto no busca aquello que necesita sino que lo hace existir» ${ }^{6}$. Esta idea, que salió de los encuentros del grupo de Rivolta, para Lonzi es muy reveladora. La cultura no acoge de manera adecuada las realidades distintas a las privilegiadas, solo las tiene presentes para justificar su situación de sometimiento. Por eso hay que hacer un esfuerzo y conseguir transformaciones que den espacio a formas de vida que armonicen con los propios deseos, iniciar el camino en el que las necesidades no sean lugares de carencia sino de activación para hacer realidad formas de vida y de relación de los seres humanos que lleven a una vida mejor y más libre.

El origen de esta propuesta, dice ella misma, ha sido el feminismo ${ }^{7}$. Lo que le ha permitido darse cuenta de todo lo que significaba la cultura (y lo que había detrás de ella) ha

6 Lonzi, C., Taci, anzi parla, p. 31 (traducción mía).

7 Lonzi, C., Taci, anzi parla, p. 243. 
sido el feminismo y los grupos de autoconciencia de Rivolta Femminile. Esto fue lo que le permitió liberarse y querer otra forma de relación, una manera de estar en el mundo más libre y auténtica, para hombres y para mujeres, porque, para ella, el feminismo posibilita la liberación: «el feminismo no solo es rabia, denuncia, sino también autoconsciencia y liberación, es todo el arco, todas las fases de un proceso: el resultado es siempre el descubrimiento de sí $[\ldots]$ que, en lugar de otra cosa, modifica la civilización» ${ }^{8}$.

La liberación a la que se refiere Lonzi es una liberación de las relaciones falsas habituales en la cultura. En la sociedad es frecuente la mentira, tanto para evitar la exclusión como para manipular a las personas en beneficio propio. En cualquier caso, las relaciones falsas e inauténticas suponen una ocultación y un obstáculo para la libertad, porque impiden hacerse una idea adecuada de la realidad y provocan que se tomen decisiones desde presupuestos inexistentes que responden a una lógica de la instrumentalización que más que mostrar lo que suele hacer es esconder los verdaderos intereses ${ }^{9}$.

Lonzi no quiere sostener afectos donde no se reconozca su trabajo, se huya de los problemas, se oculten las dificultades, se instale el miedo, la manipulación o la falta de valoración, y además se dificulte tomar conciencia de la realidad a través de palabras exageradas o no sentidas. Quiere tener lo que ella llama relaciones auténticas, que quizá se podría decir que corresponden a relaciones honestas y sinceras basadas en la confianza y la vulnerabilidad. La cultura patriarcal, sin embargo, promueve la instrumentalización: las relaciones en las que hay abuso de poder y falsedad.

Si habla de autenticidad ${ }^{10}$, y la busca, es porque Lonzi cree que es posible llegar a ella. Es más, afirma haber tenido esa experiencia con Pietro Consagra en algún momento ${ }^{11}$, lo cual significa que para ella es posible tener vínculos auténticos y satisfactorios. Aunque estos van variando con el tiempo, por supuesto, y lo que en un momento fue una relación auténtica puede no serlo más adelante. Precisamente otra de sus obras más conocidas, Vai pure, revela las dificultades de su propia relación: la de una feminista que busca una nueva forma de relacionarse, más auténtica, con su compañero de esa época, con el que en su día dijo tener experiencias de autenticidad, Pietro Consagra.

Vai pure es una publicación sin duda interesante porque es una transcripción de los diálogos que tuvieron ambos, durante cuatro días, antes de que decidieran romper la relación. En estas conversaciones se explicita lo que una feminista como ella quiere en una relación de pareja y lo que quiere un hombre que es sensible al feminismo. Lonzi busca la autenticidad porque no es un ideal utópico imposible, es viable y real: ya lo ha experimentado. Por tanto, su idea de autenticidad no tiene tanto que ver con una concepción de la verdad en sentido objetivo y absoluto sino, más bien, con conseguir el mayor alejamiento posible de la falsedad, de las mentiras y de la instrumentalización de las personas. No es, pues, una descripción de una forma de vivir determinada sino, más bien, el rechazo de la inautenticidad, la falsedad y la instrumentalización lo que, creo yo, define la relación auténtica buscada por Lonzi.

8 Lonzi, C., Taci, anzi parla, p. 161 (traducción mía).

9 Lonzi, C., Vai pure, p. 35.

10 No solo Carla Lonzi habla de autenticidad como una vía de oposición y crítica a la cultura que se caracteriza por sus mentiras y manipulaciones. Ver, por ejemplo, Firestone, S., La dialéctica del sexo, Barcelona, Kairós, 1976.

11 En 1972, Ver Lonzi, C., Taci, anzi parla, p. 70. 
Pero ¿cómo lograrlo? Esto es quizá lo más complejo aunque, al mismo tiempo, lo más interesante de la propuesta de Lonzi porque, además, coincide con la propuesta de otras feministas de aquella época: Lonzi propone iniciar ese camino a través de los grupos de autoconciencia feministas porque el feminismo es un pensamiento crítico que quiere transformar y mejorar la vida de las personas. Entre sus características no está la de adaptarse a lo dado, quiere cambiarlo, mejorarlo, hacerlo más habitable.

Los grupos de autoconciencia posibilitaron la reflexión y la toma de conciencia de todo el daño causado por una cultura patriarcal que no contempla la libertad de las mujeres, y analiza el modo en que las mujeres son construidas de forma que no parece haber lugar para ese deseo de libertad. Los roles asignados, las expectativas sociales que se tiene hacia las mujeres, lo que debe hacerles feliz, la vida que deberían llevar, etc., todo ello dificulta enormemente la propia expresión de sí. Se trata de tomar conciencia de ello y ponerlo en evidencia, de manera que se sepa lo dañino y perjudicial que es para las mujeres la cultura en la que viven. Por eso Lonzi ve ineludible construir una libertad desde el principio, porque esta posibilidad no está disponible en la cultura patriarcal.

Estos grupos fueron muy frecuentes en Estados Unidos y en algunos países europeos a finales de los años $60 \mathrm{y}$, sobre todo, principios de los 70 del siglo XX. Se trata de una preocupación común y muy difundida durante unos años. De todas las autoras, una de las que más esperanza tiene en estos grupos y en sus resultados es, precisamente, Carla Lonzi. Ella considera que es la mejor manera (aunque no la única) de ser conscientes de la instrumentalización a la que se somete a las mujeres, así como de pensar sobre las distintas maneras con las que la cultura patriarcal ha justificado y legitimado esa subordinación.

Carla Lonzi, pretende acabar con esa forma de relación y la manera más fácil y directa de hacerlo es empezar por tomar conciencia, para después modificar el propio comportamiento. Cada cual tendrá que responsabilizarse de lo que hace y arriesgar en sus relaciones si de verdad quiere una cultura no instrumental. En cierta medida, su apuesta es sencilla: construirse, de forma voluntaria y reflexiva, intentando mantener relaciones sinceras. Pero la franqueza suele poner en riesgo esas relaciones, tiene experiencia de ello.

Los conflictos y dificultades parecen inevitables pero, además, no siempre es fácil advertir que el propio comportamiento es interesado o injusto, y por eso Lonzi hace tanto hincapié en que la forma de hacer este cambio no será nunca una labor individual, no puede serlo. Es necesaria la mirada de otras personas que nos ayuden a conocernos mejor y a evitar las trampas de la autocomplacencia. En este caso, Lonzi propone la ayuda de otras mujeres (su grupo de autoconciencia estaba formado solo por mujeres ${ }^{12}$ ).

Considera imprescindible el intercambio con otras mujeres porque estima que el tener experiencias comunes, como el hecho de crecer con un cuerpo femenino en una sociedad, o los roles que se tiene en la familia, tener que enfrentarse a la posibilidad de ser madre y lo que esta decisión conlleva, etc., hace que sea más fácil la comprensión de los problemas. Por tanto, otras mujeres tendrán que ser las encargadas de hacernos ver cosas que

12 Había grupos de autoconciencia mixtos, aunque en esos casos los hombres no solían tener un papel muy activo. También había grupos que explícitamente establecían estar formados solo por mujeres, para evitar los reparos a la hora de hablar abiertamente de sus problemas con los hombres, además de para impedir que, de nuevo, los hombres sugirieran o dirigieran el deseo de las mujeres. 
quizá preferiríamos no ver, o que, sencillamente, no nos atrevemos a hacerlo, a no ser que alguien nos lo muestre y no tengamos más remedio que reconocerlo.

Los análisis y reflexiones sobre las experiencias vividas serán fundamentales para la re-construcción. Es decir, a modo de espejo, es la mirada de otras mujeres la que puede reflejar mi propio deseo, y mis miedos también. No hay forma de hacerlo individualmente, porque lo más probable es que evitemos elementos incómodos de nuestra vida, o no aceptemos los aspectos que no nos gustan de nuestra personalidad o, claro está, evitemos todos aquellos cambios que nos supongan demasiado esfuerzo. El reflejo que nos muestran las demás integrantes del grupo será lo más próximo a una posible re-composición de la imagen que se tiene de sí, de lo que se desea libremente, haciendo caso omiso de los convencionalismos sociales que solo sirven para guiar a las mujeres a lugares de sometimiento y sujeción.

Es decir, la libertad y la elaboración de una cultura más libre y auténtica no es una realización individual, no puede serlo. La construcción de sí en ningún caso puede hacerse de forma aislada. El riesgo de caer en los viejos esquemas es grande, por lo que se necesita un espejo en el que mirarnos, en el que ver la propia imagen en toda su crudeza, con sus aspectos positivos y también los negativos, sin ocultaciones.

Un espejo, por lo demás, no proporciona una imagen objetiva, ni inmutable ni permanente en el tiempo. Es la imagen ofrecida a través de la mirada de otras personas, de otras mujeres con sus experiencias y opiniones que enriquecen la propia mirada, una imagen que no será definitiva ni invariable, cambiará con el tiempo, las circunstancias, las relaciones. No es la objetividad lo que se pretende en estos grupos de autoconciencia, sino la autenticidad, y esa autenticidad conlleva incoherencias, dependencia, pasión, rebeldía... La neutralidad y la objetividad son elementos puestos en entredicho por el feminismo, por lo que no se trata de reivindicar una posición impersonal, incuestionable y embaucadora, sino auténtica, aunque no sea conveniente ni universal.

Los grupos de autoconciencia, como es fácil imaginar, no eran espacios confortables, pues sus integrantes pretendían una desculturación. Esto es, no se limitaban a escuchar las vivencias y opiniones de sus integrantes, sino que se reflexionaba sobre las experiencias narradas, pero desde una perspectiva que implicara una política feminista para poner en evidencia la forma en que nos moldea la cultura patriarcal. La crítica de la cultura es un proceso complicado por lo que supone de autocrítica, de ponerse en cuestión. En estos grupos se reconocía la situación injusta de las mujeres en la sociedad, pero también se hablaba de las trampas del patriarcado en las que ellas mismas caían, o se tomaban decisiones difíciles ante la evidencia de que llevaban vidas que no querían llevar, con el consiguiente miedo por el abandono de una cierta tranquilidad y angustia por el rechazo social. No eran lugares de apoyo amistoso y cariñoso, eran lugares de crítica y autocrítica. Eran espacios para la sinceridad y la política.

Los hombres, por su parte, también están llamados a cambiar su situación de privilegio. Lonzi no reclama que sigan los mismos pasos que las feministas, pero sí que modifiquen sus expectativas, comportamientos y relaciones una vez que se ha puesto de manifiesto que la situación de las mujeres en la sociedad no es justa (y esto es algo que no se puede dejar de reconocer). Ella tiene la esperanza de que esto suceda cuando los hombres se den cuenta de la situación, por eso, en Vai pure, Lonzi afirma que se siente 
traicionada ${ }^{13}$ porque Pietro Consagra, su compañero, no quiere de ninguna manera hacer una crítica profunda a la cultura, todo lo contrario, se aprovecha de ella y se beneficia lo que puede de la fama que tiene como artista reconocido. Con ello, quiera o no, sostiene y reproduce una cultura basada en las relaciones falsas y en la instrumentalización. Siendo consciente de que la situación de las mujeres es casi invivible, porque ella así se lo ha explicado, él no hace nada por transformarla. Se aprovecha de ser un hombre apoyado por la cultura.

Sin embargo, con todo, considera que, igual que los hombres no deben decir la forma en que deben ser libres las mujeres ni lo que deben desear en sus vidas, tampoco las mujeres deben hacer nada parecido con los hombres. Ellos deben encontrar la vía que mejor les parezca, pero, eso sí, es preciso que inicien el camino del cambio. La situación de injusticia y la vida invivible de las mujeres es algo que no se puede ocultar por más tiempo, no se puede seguir sosteniendo una cultura tan dañina para la psique y la vida de más de la mitad de la población. Para Lonzi la transformación es absolutamente necesaria. Hay que conseguir que la cultura no menosprecie a las mujeres y que reconozca su valía, sus capacidades, sus obras y sus aportaciones a la sociedad. Una nueva forma de entender las relaciones humanas y de valorar a las personas dejará atrás errores pasados que han hecho tan difícil la vida de tantas mujeres.

\section{Bibliografía}

Boccia, Maria Luisa (1990): L'io in rivolta. Vissuto e pensiero di Carla Lonzi, La Tartaruga, Milán.

Boccia, Maria Luisa (2014): Con Carla Lonzi. La mia opera è la mia vita, Ediesse, Roma. Chinese, Maria Grazia, Lonzi, Carla, Lonzi, Marta y Jaquinta, Anna (1977), È già politica, Scritti di Rivolta Femminile, Milán.

Conte, Lara, Fiorino, Vinzia y Martini, Vanessa (ed.) (2011), Carla Lonzi: la duplice radicalità. Dalla critica militante al Femminismo di Rivolta, Edizioni ETS, Florencia.

Diotima (2003), Il pensiero della differenza sessuale, La Tartaruga, Milán.

Diotima (1996), La sapienza di partire da sé, Liguori, Nápoles.

Diotima (2002), Approfittare dell'assenza. Punti di avvistamento sulla tradizione, Liguori, Nápoles.

Librería de mujeres de Milán (2004), No creas tener derechos. La generación de la libertad femenina en las ideas y vivencias de un grupo, Horas y horas, Madrid.

Librería de mujeres de Milán (2006), La cultura patas arriba. Selección de la Revista Sottosopra (1973-1996), Horas y horas, Madrid.

Lonzi, Carla (1975), Escupamos sobre Hegel. Y otros escritos de Liberación femenina, La Pleyade, Buenos Aires.

Lonzi, Carla (1978), «Mito della proposta culturale», en Lonzi, Marta, Jaquinta, Anna, Fonte, Moderata y Lonzi, Carla, La presenza dell'uomo nel femminismo, Scritti di Rivolta Femminile, n. 9, Milán, pp. 137-154.

13 Lonzi, C., Vai pure, p. 10. 
Lonzi, Carla (1992), Armande sono io!, Scritti di Rivolta Femminile, Milán.

Lonzi, Carla (2010), Taci, anzi parla. Diario di una femminista, vol. I (1972-1973) y vol. II (1974-1977), Et al. Edizioni, Milán.

Lonzi, Carla (2011), Vai pure. Dialogo con Pietro Consagra, Et al. Edizioni, Milán.

Lonzi, Marta y Jaquinta, Anna (1985), «Biografia», en Lonzi, Carla, Scacco ragionato. Poesie dal '58 al '63, Scritti di Rivolta Femminile, Milán, pp. 9-73.

Millett, Kate (2010), Política sexual, Cátedra, Madrid.

Rivera Garretas, María-Milagros (2005), La diferencia sexual en la historia, Publicacions de la Universitat de València, Valencia. 